\title{
ELECTRONIC HEALTH RECORD SYSTEMS; PERCEPTION AND EVALUATION AMONG PHYSICIANS IN PAKISTAN
}

1. Professor of Biochemistry Amnay Inayat Medical College, Lahore

2. Assistant Professor surgery Amna Inayat Medical College, Lahore

3. Assistant Professor Gynaecology Amna Inayat Medical College, Lahore

4. UOL Lahore.

5. HOD, UIPH, UOL, Lahore

6. Assistant Professor

UOL, Lahore.

7. Allama lqbal Medical College. Lahore

8. Allama Iqbal Medical College, Lahore

9. Amna Inayat Medical College, Lahore

Correspondence Address:

Dr. Hamid Mahmood

Professor of Biochemistry

Amna Inayat Medical College, Lahore

drhamidmahmood373@gmail.com

Article received on:

$17 / 12 / 2015$

Accepted for publication:

$15 / 10 / 2016$

Received after proof reading:

$18 / 01 / 2017$
Dr. Hamid Mehmood', Dr. Muhammad Aslam², Dr. Sadia Aslam³, Ammara Waqar ${ }^{4}$, Dr. Athar Khan ${ }^{5}$, Yasir Hassan $^{6}$, Dr. Faryal Murtaza Cheema7, Dr. Hassan Mujtaba ${ }^{8}$, Noor-e-Maham ${ }^{9}$

ABSTRACT...Introduction: e-Health is a combination of medical informatics, public health, business and information technology. Health information technology has increased the productivity by reengineering of health care but it requires new measurement tools to monitor the impact of it .e-health is not only for the development of technologies but also it includes proper planning, thinking, broad thinking to improve healthcare services with the help of information and communication technology. Objectives: 1) To assess the perceptions of physicians towards the use, effectiveness and efficiency of EHR 2) To identify the differences between electronic and paper based records 3) To evaluate the usage of Electronic Health Records.4) To analyze satisfaction and challenges face by the physicians using EHR. Research Design: This is an Exploratory and Descriptive Research. In this study hybrid research method is used which includes qualitative and quantitative research methods. Sampling technique: For this study, a purposive sample of 43 physicians was selected. The sample size was 60 but 17 responses were incomplete so they were excluded and the final sample size was 43 . Data was collected from two different hospitals of Pakistan which include the physicians from Shaukat Khanum Memorial Cancer Hospital and Research Centre, and Indus Hospital. Of the 43 participants, $51 \%$ were from Indus Hospital and $49 \%$ were from Shaukat Khanum Memorial Cancer Hospital and Research Centre. Instrument: A structured questionnaire was used to collect data and it was collected by email responses and direct interview. EHR Questionnaire: A questionnaire was used in the study. The EHR Questionnaire has comprised of 24 items. This questionnaire was developed by Msukwa. B.K.Martin. ${ }^{1}$ Data Analysis: Data analysis was done by Statistical Package for Social Sciences (SPSS) and Microsoft Excel. Procedure: The sample consisted of physicians from Shaukat Khanum Memorial Cancer Hospital and Research Centre, and Indus Hospital from Karachi. EHR is a new technology and hospitals are moving towards it, some are under process and very few like the above mentioned hospitals are using it. The questionnaire was not complicated. It was a structured questionnaire with easy questions with multiple options to fill in. Respondents were also acknowledged for their cooperation and participation in the study. Conclusion: EHR should be used effectively, proper training is needed to ensure that physicians are able to operate the system and can have maximum benefits from the technology by utilizing all its applications. The government should encourage adoption of Electronic Health I Records in Pakistan by developing a public-private partnership. The study focused also on EHR effectiveness by checking the working of EHR its quick and satisfactory results its accuracy, adequacy, timeliness, user- friendliness, availability and reliability.

Key words: $\quad$ Evaluation, Perception, Electronic Health Records, Physicians.

Article Citation: Mahmood H, Aslam M, Aslam S, Waqar A, Khan A, Hassan Y, Cheema FM, Mujtaba H, Noor-e-Maham. Electronic health record systems; perception and evaluation among physicians in Pakistan. Professional Med J 2017;24(1):182187. DOI: $10.17957 / T P M J / 17.3213$

\section{INTRODUCTION}

E-Health is an advance term which has brought a revolution in the healthcare industry by using information and communication technologies. It was introduced in $1999 .^{2}$

e-Health is an combination of medical informatics, public health, business and information technology. Health information technology has increased the productivity by reengineering of health care but it requires new measurement tools to monitor the impact of it. ${ }^{3}$ 
technologies but also it includes proper planning, thinking, broad thinking to improve healthcare services with the help of information and communication technology. ${ }^{2}$

The TWAS-hosted 13th annual meeting of the Coordinating Council of the Commission on Science and Technology discussed about the successful steps taken by COMSATS. It has developed 16 centers of excellence. ${ }^{4}$

In this meeting, The COMSATS Institute of Information Technology (CIIT) in of Pakistan proved to be one of the prosperous institutions. COMSATS Institute of Information Technology (CIIT ) started a project named as COMSATS Internet Services (CIS) to build up an IT infrastructure.

eHealth has allowed for online medical care and has improved the basic healthcare services even in the locations where accessibility is very difficult. It is progressing day by day and now three large hospitals are expanding eHealth technologies.

The pilot project of Aga Khan University is to improve the e-Health Services in Northern Pakistan by and funds of Aga Khan Foundation, Geneva. The main goal of this project is to provide mobile technologies such as GPRS in villages where there are no services and satellite connectivity is blocked because of border restrictions.

This project will develop a tele-consultation link for patient management including referral of $\mathrm{MCH}$ using e-Health services. It has also aimed to start e-learning programmes and improve monitoring. ${ }^{5}$

E-health provides good quality of care to the patients and help the healthcare professionals to make better decisions, patients are more aware of their rights and they take responsibility of their own health. Now Government is also taking interest in health needs and supporting the development of health information systems in the country. Due to e-health services people are aware of risks and prevention of diseases. ${ }^{6}$
Like other developing countries Pakistan started using information and communication technology in healthcare. It is not implemented in the country as a whole because of limited resources and also it could be because clinicians are not trained to use the technology.

The above figure shows the networking and

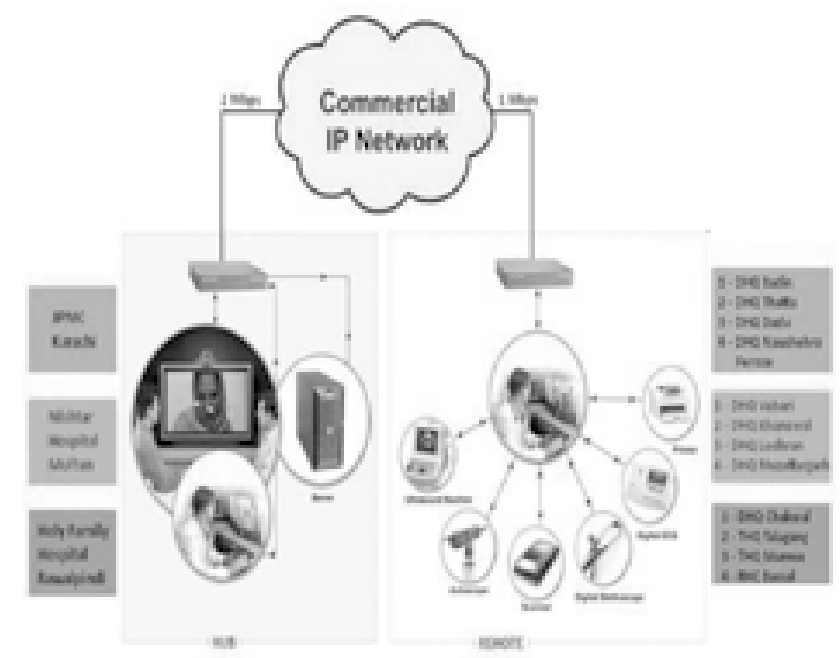

Figure-1. Telemedicine Network \& Services

services for telemedicine. The services are provided in JPMC Karachi, Nishtar Hospital Multan, Holy Family Hospital Rawalpindi and many other remote hospitals like DHQ Badin, DHQ Thatta, DHQ Dadu, DHQ Naushera Feroze, DHQ Vehari, DHAQ Khanewal, DHQ Lodhran, DHQ Muzaffargarh, DHQ Chakwal, THQ Talagang, THQ Murree and RHC Bassal.

In spite of all the hurdles this is the fact that e-Health is very important mainly because mostly the population of Pakistan is living in rural areas which are not accessible so there is a need of information and communication technologies to provide better delivery of health care equally to all.

The above figure shows Architecture of EHR. There are many computer systems which are linked to the EHR application server. It contains a database system all are connected with different departments like Pharmacy, Laboratory and Radiology. 


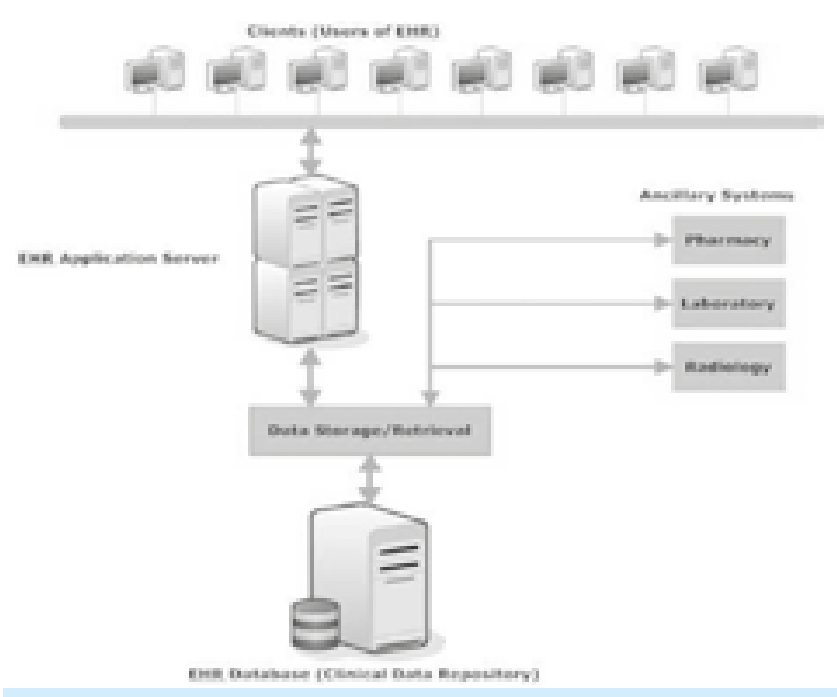

Figure-2. Architecture of HER

It should assist the physicians in making decisions at the right time. The aim of EHR should be also to provide security to the medical records of the patients considering ethical and legal issues. It should be utilize for secondary purposes such as research, quality assurance and policies regarding healthcare.

\section{History of EHR}

Lawrence L. Weed a physician in 1960s first introduced Electronic Health Records. He suggested a system which can save medical records of the patients in the electronic form to improve the delivery of care. This work started at the University of Vermont in 1967 to convert paper based medical records into electronic form. The health care professionals and the IT experts developed a problem oriented medical record. In the same year Mayo clinic started developing Electronic Medical Record System.

In 1970theproblem oriented medical record started working in a medical ward of the Medical Centre Hospital of Vermout. Touch screen technology was introduced and then drug information was added to the system for the doctors to check the dosages, side effects, diagnostic and treatment plans etc. Many research institutions were involved in the process of implementing an EHR and it increased during 1970s and 1980s. The inpatient systems were introduced by The Help system and Duke the Medical Record system. Registries record introduced the combination of both in patient and out patient's records system.

With the advancement of Information and Communication Technologies many more features were introduced in the EHR. In the $21^{\text {st }}$ century it is becoming a compulsion to install the EHR in the hospitals. ${ }^{7}$

\section{SUBJ ECTS \& METHODOLOGY}

\section{Research Design}

This is an Exploratory and Descriptive Research. In this study hybrid research method is used which includes qualitative and quantitative research methods.

\section{Sample}

For this study, a purposive sample of 43 physicians was selected. Data was collected from two different hospitals of Pakistan which include the physicians from Shaukat Khanum Memorial Cancer Hospital and Research Centre, and Indus Hospital. Of the 43 participants, $51 \%$ were from Indus Hospital and $49 \%$ were from Shaukat Khanum Memorial Cancer Hospital and Research Centre.

\section{Instrument}

A structured questionnaire was used to collect data and it was collected by email responses and direct interview.

\section{EHR Questionnaire}

A questionnaire was used in the study which comprised of 24 items. This questionnaire was developed by Msukwa. B.K.Martin.

\section{DATA ANALYSIS}

Data analysis was done by Statistical Package for Social Sciences (SPSS) and Microsoft Excel.

\section{PROCEDURE}

The instruments were administered after taking the consent. Respondents were briefly informed about the purpose of the study. Full information was given to them and they were allowed to ask any question in case of confusion. After handing over the scale, they were asked to read the 
instructions carefully and were assured about the confidentiality of their responses. Some of the part of data was collected through emails.

The sample consisted of physicians so the data was collected from hospital of Lahore which was Shaukat Khanum Memorial Cancer Hospital and Research Centre, and Indus Hospital from Karachi. It was a structured questionnaire with easy questions with multiple options to fill in. Respondents were also acknowledged for their cooperation and participation in the study.

\section{RESULTS}

The present study is designed to investigate the perception and evaluation of electronic medical record systems among physicians in Pakistan. For this purpose physicians of different hospitals were selected to fulfill the objectives of the study. This study used one questionnaire.

Age of physicians using of Electronic Health I Records

\begin{tabular}{|c|c|}
\hline Age in years & Frequency (\%) \\
\hline $20-25$ & $4(09)$ \\
\hline $26-30$ & $11(26)$ \\
\hline $30-35$ & $16(37)$ \\
\hline $36-40$ & $06(14)$ \\
\hline 41 and above & $06(14)$ \\
\hline Table-l. Age distribution of physicians using EHR \\
$(\mathbf{N}=43)$.
\end{tabular}

The above table shows show that there were 04 physicians of the age group 20-25 years,
11 physicians of the age group 26-30 years, 16 physicians of the age group 30-35 years, 6 physicians of the age group 36-40 years and 06 physicians of the age group 41 and above out of 43 physicians. The minimum age group was 20 25 and the maximum age was 41 and above. This was calculated by SPSS.

The results in table 5 shows there were 12\% physicians with having experience less than 6 months, $14 \%$ with experience of 6-12 months, $16 \%$ with experience of $13-18$ months, $26 \%$ with experience of $19-24$ months and $32 \%$ with experience of above 20 months. The study revealed that $75 \%$ of participants had used the EHR for more than six months.

\section{DISCUSSION}

Pakistan is a developing country. Like other developing countries Pakistan is also moving towards electronic systems to improve the healthcare delivery system. In this study two hospitals were selected to be included in the research. There are many hospitals that are moving towards technology and Electronic Medical Record Systems. Mostly have started but not fully implemented the system. Lack of professionalism among workers, corruption, false data entry to create revenue and lack of evaluation and monitoring put the system in great difficulty. ${ }^{8}$

There are very few researches on Electronic Medical Record with reference to Pakistan. So this study was planned in order to find out working of Electronic Medical.

\section{Experience of physicians}

\begin{tabular}{|l|c|c|c|}
\hline \multicolumn{1}{|c|}{ Time Period } & $\begin{array}{c}\text { Period worked in the } \\
\text { Hospitals (\%) }\end{array}$ & $\begin{array}{c}\text { Period used paper based } \\
\text { records (\%) }\end{array}$ & Period used EHR (\%) \\
\hline less than 6 months & $5(12 \%)$ & $6(14 \%)$ & $11(26 \%)$ \\
\hline $6-12$ months & $6(14 \%)$ & $7(16 \%)$ & $8(19 \%)$ \\
\hline $13-18$ months & $7(16 \%)$ & $9(21 \%)$ & $10(23 \%)$ \\
\hline $19-24$ months & $11(26 \%)$ & $10(23 \%)$ & $9(21 \%)$ \\
\hline above 24 months & $14(32 \%)$ & $11(26 \%)$ & $5(12 \%)$ \\
\hline Total & $43(100 \%)$ & $43(100 \%)$ & $43(100 \%)$ \\
\hline
\end{tabular}

Table-Il. Experience of physicians with respect to usage to Paper based records, Electronic records and overall working period in hospitals 
Records and the satisfaction of physicians due to this technology. The Indus hospital is the Pakistan's first paper less hospital. Indus Hospital started its journey in $1^{\text {st }}$ July 2007 . It is free of cost. In $23^{\text {rd }}$ June 2008, the Indus Hospital registered as Company under section 42 of Companies Ordinance. It is running its own Hospital Management.

Information System which is fully computerized and truly paperless system based on Oracle. There International Collaborations are with Harvard school of Public Health, University of Texas Health Science Center, MIT, University of lowa, Partners in Health and MSF.

The second hospital which was selected for investigation was Shaukat Khanum Memorial Hospital and Research Centre. Shaukat Khanum Memorial Hospital and Research Centre was established in 1994, it is recognized as one of the credible hospital to provide quality care to patients free of cost. The accreditation is from AACME (American Academy of Continuing Medical Education) since August 2009. It is under the project of Shaukat Khanum Memorial Trust. It has spent over Rs. 9 billion in treatment and currently $75 \%$ of patients are receiving treatment by financial support. It has 1,524 consultants, physicians \& surgeons. Shaukat Khanum Memorial Hospital is running Hospital Management Information System (HMIS).

NetSol Technologies Inc has developed a partnership with Shaukat Khanum Memorial Cancer Hospital for IT development in the worldwide health sector. NetSol's Hospital Management Information System (HMIS) solution provides day to day office operations for proper management of administration. It is using integrated machines like PACS that is Picture Archiving and Communication System. Shaukat Khanum Memorial Hospital is using EHR with Oracle Database (Hybrid database (OLTP/DSS); 24x7 availability).

Limitations and Suggestions

Before implementing an EHR we should apply change management which is an approach to shift organization from the current state to future state. There are operational changes, technological changes and behavioral changes. We should focus on behavioral changes more because physicians are used to of making decisions by their own for the patients and writing prescriptions on the paper. They feel they are expert in their field so they don't need the technology. There should be awareness programs about the benefits of EHR before implementing an EHR to convince the physicians to adopt the technology.

In Pakistan there are only few hospitals using EHR which are also not taking the full advantage of it. There are many EHR systems with no communication if there is one system in the whole country it would be perfect in communication as well as useful for the policy makers and researchers to access the data and make developments.

\section{CONCLUSION}

Electronic Health Records provide many benefits to all the stakeholders of healthcare system. It will become standard of care in the near future. The initiatives of evaluating EHRs in Pakistan in this study will hopefully give an idea of the benefits and user satisfaction through EHR. The government should encourage adoption of Electronic Health I Records in Pakistan by developing a publicprivate partnership. Overall in this study the physicians were satisfied with the working of EHR. In their opinion there is a significant change in the quality of care provided to the patients and also the waiting time is reduced. The training should have a proper curriculum and should be updated from time to time. The study used perceptions of doctors to evaluate the efficiency and usage of the EHR system which includes quality data, user friendly and patients and physicians satisfaction. The study focused also on EHR effectiveness by checking the working of EHR its quick and satisfactory results its accuracy, adequacy, timeliness, user- friendliness, availability and reliability.

Copyright (C) 15 Oct, 2016. 


\section{REFERENCES}

1. Msukwa.M,http://www.medcol.mw/commhealth/mph/ dissertations/martin\%20msuk wa_Approved.pdf, 2011.

2. Della. V, http://www.jmir.org/2001/2/e22/, 2012.

3. Rand. Cooperation,http://www.rand.org/topics/electronic-medical-records.html,2012.

4. Twast,http://twas.ictp.it/news-in-home-page/news/ ehealth-in-pakistan,2012.

5. Anwar. S, http://healthmarketinnovations.org/program/ improving-health-services-North-Pakistan-throughehealth, 2012.

6. Parras. S, http://www.technologytimes.pk/2012/03/03/ health-for-all-e-health-in-Pakistan-prospective/, 2012.

7. Pinkerton. K, http://ezinearticles.com/?History-Of-Electronic-Medical-Records \& id $=254240$.

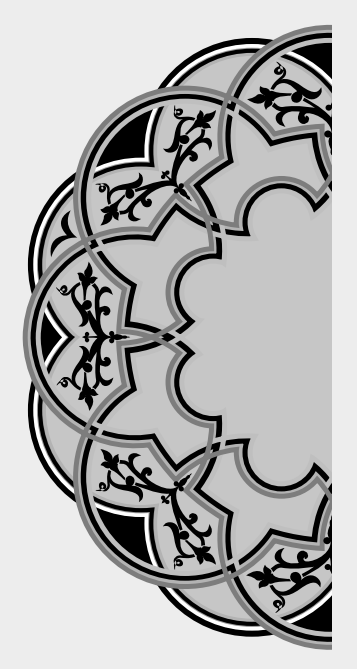

\title{
"If you want to fly, you have to give up the stuff that weights you down."
}

\author{
Unknown
}

\section{AUTHORSHIP AND CONTRIBUTION DECLARATION}

\begin{tabular}{|c|l|}
\hline Sr. \# & \multicolumn{1}{|c|}{ Author-s Full Name } \\
\hline 1 & Dr. Hamid Mehmood \\
2 & Dr. Muhammad Aslam \\
3 & Dr. Sadia Aslam \\
4 & Ammara Waqar \\
5 & Dr. Athar Khan \\
6 & Yasir Hassan \\
7 & Dr. Faryal Murtaza Cheema \\
8 & Dr. Hassan Mujtaba \\
\hline 9 & Noor-e-Maham \\
\hline
\end{tabular}

Contribution to the paper
Researcher
Co-researcher
Data Collection
Data Analysis
Sata Analysis
References
References
References

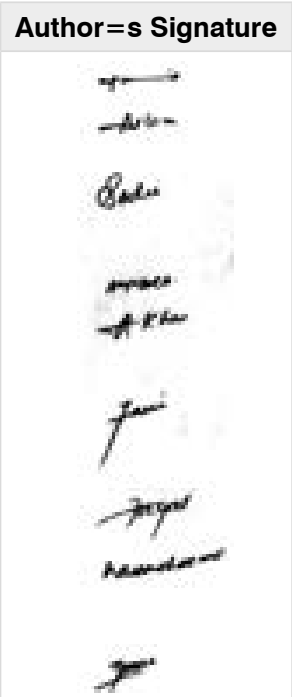

